\title{
Gaúchos em Roraima: memória, regionalismo e identidade
}

\author{
Carla Monteiro de Souza*
}

\begin{abstract}
Resumo: O objetivo deste artigo é discutir um perfil identitário do gaúcho que vive em Roraima, tendo entrevistas orais como principal suporte documental. Através da abordagem da categoria regionalismo, observa que a relação entre espaço, cultura e origem regional é geralmente naturalizada, conferindo um forte conteúdo identitário a essas narrativas.
\end{abstract}

Abstract: The objective of this article is to discuss a profile identifying people from Rio Grande do Sul that live in Roraima, working with oral interviews as the mainly upholding document. Through the approach of the regionalism category, it also observes that the relation among space, culture and regional origin is generally naturalized, with a strong content of identity of these narratives.

Palavras-chave: Identidade. Regionalismo. Oralidade.

Key words: Identity. Regionalism. Orality.

Viver em outro lugar, reestruturar relações humanas, espaciais e temporais é tarefa complexa. A convivência do migrante com os "da terra" é exercida em via de mão dupla, na qual o movimento de desenraizar e enraizar é constante, variando de acordo com muitas situações específicas.

Ao contar a sua história, o migrante produz um texto que busca atender a si mesmo e ao ouvinte. A objetividade deste texto está alicerçada em um certo repertório de habilidades e informações culturalmente situadas em "quadros de referência", cuja abordagem é necessária para a compreensão dos "conteúdos" das narrativas. Ao falar de si o migrante é, a um só tempo, o produtor

Doutora em História. Professora no Departamento de História da Universidade Federal de Roraima - UFRR. E-mail: carlamont59@uol.com.br.

Estudos Ibero-Americanos. PUCRS, v. XXXII, n. 1, p. 199-207, junho 2006 
e um decodificador de narrativas, começando pelas suas próprias. Produzir uma narrativa envolve essencialmente a manipulação de inúmeros elementos, como códigos, valores, crenças, normas, alguns familiares outros nem tanto (Jobim, 2003, p. 149).

A narrativa produzida no momento da entrevista parte daquilo que o migrante considera ser o seu começo, suas origens e elementos constituintes. Situados no passado e articulados com o presente, estas referências justificam e dão consistência à mensagem que deseja transmitir. Ao narrar vai além da sua individualidade e, como explica José Luis Jobim, faz "uso da herança cultural em que se enraíza a própria existência da narrativa, como uma forma possível de dar sentido ao real" (2003, p. 150).

A forma como os migrantes gaúchos entrevistados narraram as suas vidas, fala sempre sobre quem são, sobre os lugares ocupam no espaço, sobre a temporalidade a que se vinculam; falam de processos e de episódios, de tempos longos e curtos, do geral e do particular, do familiar e do estranho, do eu e do outro; falam de identidade e de pertencimento.

Na discussão sobre identidade e pertencimento, busco respaldo na concepção não-essencialista, que focaliza as diferenças e as características comuns partilhadas pelo grupo, estando a identidade vinculada a condições materiais e sociais, relativamente a outras identidades - "nós e eles" (Woodward, 2000, p. 12-15). Neste sentido, o social e o simbólico são necessários para a definição e a manutenção das identidades, que não são unificadas ou homogêneas. Podem haver discrepâncias entre os níveis individual e coletivo, sendo fundamental definir o contexto em que se dão os múltiplos encontros vivenciados. Ao pensar identidade destaco: que ela é produzida em momentos particulares no tempo; que é portadora de um núcleo essencial que distinguiria um grupo do outro; que também é contingente, ou seja, é produto da intersecção de diferentes componentes (Hall, 2000, p. 108).

De maneira geral, a identidade é tomada como referencial para a diferença: que se é torna-se o ponto de partida para definir o outro. Tomaz Tadeu da Silva coloca muito bem que, em essência, é a diferença que vem em primeiro lugar (2000, p. 74-76). Identidade e diferença formam um binômio, devendo se pensadas como categorias complementares e inseparáveis.

Este aspecto foi observado em todas as narrativas coletadas. Falando de si mesmos, os gaúchos falam dos outros, em sentido mais amplo ou particularizado. No momento da entrevista buscaram recursos narrativos que dessem sentido ao que estava sendo dito. A confrontação foi um dos mais expressivos, bem como o 
dualismo, expresso através de oposições bem claras, que diferenciam, estabelecendo desequilíbrios necessários, ensejando relações de poder, sistemas classificatórios, um certo ordenamento da vida social, que explicita divisões - ao menos em dois grupos, "nós/eles" - e exclusões. Nas falas sobressai o caráter performativo das identidades, ou seja, o "tornar-se", definido através de exclusão e inclusão, afastamento e proximidade, estranhamento e afinidade. Na fala dos migrantes gaúchos expressam, por um lado, esquemas de oposição binária, por outro, buscam comunicar situações complexas, que envolvem mediação e/ou negociação.

Ser gaúcho em um outro lugar, implica atos, ações, falas e discursos nem sempre possíveis e viáveis. Contudo, a narrativa provocada pelas indagações do investigador foge ao cotidiano. É possível aos narradores "se soltarem", aproveitando a oportunidade para falar de assuntos que não são falados a muito tempo, ou que já foram esquecidos, ou que foram afastados por serem inconvenientes. Na formulação mais apurada das narrativas, buscaram maneiras eficientes de lembrar e narrar, a fim de conferir intelegibilidade, força, eficácia e legitimidade ao discurso identitário.

O desvelamento do passado foi parte importante no processo de narrativa da identidade migrante (Woodward, 2000, p. 17-18). Os gaúchos entrevistados evocaram uma origem referenciada em um passado histórico, um passado "real" e consolidado, de domínio coletivo e individual que validou a identidade reivindicada. Nos textos construídos a identidade regional gaúcha adquiriu prestígio e reconhecimento, pois demarcou um espaço, definido como diferente e particular no todo nacional.

Estabeleceu-se uma relação entre presente e passado, segundo a qual tudo de bom ou de ruim, de útil ou inútil, ainda que manifestação do presente, estava geralmente alicerçado ou relacionado ao passado. O passado "real" e consolidado define suas marcas a partir de sempre, explica o "eu" e o "outro", define estranhamento e pertencimento.

O passado narrado é história, na qual memória e linguagem e seus surpreendentes recursos ensejam o que Stuart Hall chama de "narratização do eu" (2000, p. 109). As narrativas possibilitaram ao migrante gaúcho, ao menos naquele momento, a produção de uma versão de si próprio, ou seja, sua história pessoal, tornando-o ele mesmo em um lugar de "outros".

Dito isso, abordo uma das categorias que propiciaram configurar um perfil identitário do gaúcho que vive em Roraima: regionalismo. 
A discussão acerca do regionalismo é rica e intrincada e está ligada, tradicionalmente, ao aspecto político. Aqui, a noção de regionalismo é ampliada, tendo como princípio o fato de que todo ser humano estabelece vínculos com o seu lugar de origem, no qual reconhece referênciais e diacríticos. Existe um certo "enraizamento" territorial original que impregna o ser dos indivíduos e suas relações, ainda que situações de mobilidade social e deslocamento geográfico ampliem o seu raio de visão e de atuação. Região, regionalismo, territorialidade, identidade regional e territorial são termos pensados de maneira complementar e interagente.

A identidade regional do gaúcho é reconhecidamente bem definida. Nas falas aqui referenciadas, ${ }^{1}$ o perfil autoconstruído do migrante gaúcho implica ousadia: ele sai para tentar a vida, com sua vontade e recursos. Estas imagens definem uma categoria social englobante, o migrante gaúcho: o gaúcho é meio andarengo, anda para todo lado, tem gaúcho em todo canto do Brasil.

Falando de si ou de situações objetivas - como trabalho ou negócios - recorrem às comparações, tais como aquelas relacionadas ao meio físico - qualidade das terras, clima, vegetação -, à estrutura sócio-econômica do estado - quando comentam o papel do setor público e da livre iniciativa no desenvolvimento regional -, ao estilo de vida - quando fala em trabalho, lazer, costumes, alimentação. Embora boa parte das comparações tendam a ser mais elogiosas em relação ao Sul, algumas equilibram a balança. É interessante destacar que o clima frio e a situação sócio-econômica do Rio Grande do Sul foram os dois elementos mais destacados como negativos, inclusive sendo colocados como empecilho para um possível retorno.

No entanto, o Rio Grande do Sul é o seu lugar, no sentido dado por Certeau, quando afirma que "um lugar é uma ordem, segundo a qual se distribuem elementos nas relações de coexistência" (1994, p. 201). Por mais integrados que os narradores se considerem e se assumam, deixaram claro que a sua base formadora, que orienta a sua vivência, está radicalmente alicerçada na sua origem, evidenciando-se a associação entre espaço/cultura. O lugar de origem e o de adoção são duas coisas distintas, ainda que

1 As narrativas aqui mencionadas compõem o corpus documental da tese "História, memória e migração: processos de territorialização e estratégias de inserção entre migrantes gaúchos radicados em Roraima", defendida em março de 2004, junto ao PPG-História da PUCRS. Foram realizadas sete entrevistas abertas com gaúchos residentes a mais de 15 anos em Boa Vista (capital). Todas as citações dessas entrevistas serão feitas em itálico. 
no momento da narrativa se cruzem e se justaponham, justificando o fato de ser assim hoje e aqui, porque nasci e me criei lá.

Este jogo com o tempo expressa também uma noção de perenidade em relação ao estado natal:

[...] veja que eu estou com setenta e três anos, completos, e ainda hoje eles estão plantando nos mesmos locais e a terra está produzindo, porque comparada com a terra de Roraima, não tem onde empatar com a terra do Sul. Aqui é bom para se viver mas as terras não ajudam a agricultura.

A concepção de que o Rio Grande do Sul constitui uma sociedade severa, ordeira, disciplinada e conservadora também compõe esta noção de perenidade: “[...] porque aqui em Roraima tudo que é impossível acontece, tudo. Mas a vida é boa viu, porque não tem aquela etiqueta, como tem lá no sul [...]”.

Em contrapartida, a informalidade e o ineditismo associados à Roraima têm duplo sentido: é positivo, pois é algo que facilita a vida, tornando-a mais simples; mas também é negativo, pela falta de certos padrões e convenções. Associadas, as noções de perenidade e de imutabilidade definem uma sociedade na qual haveria pouco espaço para a inovação. O novo é associado à frente de expansão, à fronteira, onde a realidade é mais dinâmica, onde tudo está em formação; é o outro, o lugar onde tudo é e pode ser diferente.

O discurso regionalista tem forte conteúdo identitário (Bourdieu, 1989, p. 116-117). A sua eficiência repousa na fala dos indivíduos que o assumem e o legitimam, como no trecho a seguir, que pode ser apontado como um exemplo típico do discurso regional gaúcho:

Eu ainda acho um dos estados com maior potencial, a questão da agricultura no RS ainda é forte, mas tem potencial industrial. [...] lá o pessoal não espera que as coisas venham do céu, nem espera que o governo venha dar tal coisa. Porque o RS desde o início teve que lutar por tudo que precisou, teve que lutar até pelo Brasil com os vizinhos, para manter o que hoje é do Brasil. Então eu acho um povo que não tem que esperar as coisas, é um povo que vai a frente, claro que com a crise tem até outros estados que estão sobressaindo, mas eu ainda acho que o RS, para se viver, se não é o melhor é um dos melhores do país.

Esta fala, a um só tempo, distingue, qualifica e engloba: o bom conceito atribuído à região expressa também o conceito que o migrante se atribui. Da mesma forma, a interação entre o social/regional e o individual também é visível quando falaram de 
progresso e de sucesso, sempre associados ao trabalho duro e à livre iniciativa:

[...] O trabalho lá é um negócio, que é levado a sério, tem aquele negócio lá de fazer as coisas por si próprio [...] aqui é um estado que gira em torno do serviço público federal, que deixa um pouquinho a desejar e no RS isso não tem um poder muito grande na economia.

A questão da livre iniciativa e da auto-suficiência local - toda casa tinha seu parreiralzinho, sua horta, vaca, porco, galinha, seu queijo e seu salame - são importante na composição do perfil regional. Liga-se ao modo de vida da fronteira e da estância, mas, em grande parte, vincula-se ao estilo de vida das áreas onde houve imigração não lusitana, salientando-se a figura do colono.

[...] a questão de ter cultura alemã e italiana lá, um pessoal que já tinha uma estrutura, uma sociedade muito mais organizada que a nossa [...] o que ficou pra gente lá, foi que eles pegaram uma região totalmente inexplorada e eles construíram com as próprias mãos.

Os marcadores regionais constituídos a partir da imigração são apontados de forma recorrente como um importante diferencial humano e cultural do Rio Grande do Sul. Funcionaram, inclusive, como elemento explicativo e justificador da migração: "O gaúcho que sai tem esse sanguezinho italiano ou alemão por trás, [...] dos que vieram para cá (Roraima), poucos são "brasileiros" puros, todos tem esse sanguezinho estrangeiro nas costas".

Não obstante, a primeira imagem associada ao gaúcho é a do homem tradicionalmente paramentado. E não é a toa. Segundo um dos narradores, onde se juntam três gaúchos querem montar um CTG, como se essa fosse uma decorrência "natural", um impulso inato de reproduzir e perpetuar os marcadores e diacríticos regionais através das práticas e manifestações do Tradicionalismo.

O Tradicionalismo, também é naturalizado, estando associado a elementos como o clima temperado, o meio ambiente, as quatro estações, assim como a um certo tipo de indivíduo que habita este lugar, produto do "amálgama étnico" de imigrantes europeus, açorianos, índios, peões da fronteira, castelhanos. Nas falas dos gaúchos entrevistados, a Tradição é tratada como marcador de identidade e credibilidade, como elemento diferenciador, independentemente da filiação étnica do indivíduo.

Junto à Tradição, o chimarrão também é naturalizado: "muitas pessoas acham que a pessoa está querendo se mostrar [...] fazer uma onda, mas [...] é um costume, uma tradição que o pessoal tenta manter". O chimarrão sendo mais que um hábito, é uma prá- 
tica cultural, uma manifestação regionalista do "ser" gaúcho. Como outros elementos da identidade regional gaúcha também naturalizados, o chimarrão foi descrito em uma das narrativas como uma "necessidade", acrescentaria, visceral.

Como o chimarrão, a iniciativa de aglutinação em torno do CTG também foi justificada como "uma carência que a gente tem de participar das coisas do sul, como uma necessidade natural, como uma [...] atração natural que não se sabe explicar". Esses momentos de carência e saudade são vivenciados no CTG Nova Querência (Boa Vista) - que é um dos grandes clubes da capital, com associados de todos os estados - que cumpre as suas funções básicas, propiciando e promovendo várias manifestações regionalistas e, principalmente, a Semana Farroupilha coisas que, no dizer de um dos narradores, só podem ser apreciadas ali.

Por outro lado, em algumas das narrativas ficou claro que a vinculação à Tradição e/ou ao CTG se tornou mais importante a partir da migração. Com exceção de um dos entrevistados, todos os outros se encaixavam nesta situação: "aqui [Roraima] foi uma força tão grande que virei um gaúcho daqueles autênticos mesmo; lá [Rio Grande do Sul], a gente ia a baile e coisa e tal, mas não participava ativamente do movimento gaúcho".

Esta conexão mais estreita com a cultura regional gaúcha foi explicada como um apego aos costumes e justificada, mais uma vez, por um processo naturalizado: haveria uma "absorção" dos costumes desde a infância. Para todos os entrevistados, a bagagem cultural é indissolúvel e inalienável, algo que não se perde com a mudança de lugar e de situação de vida, ainda que descrevam com bastante clareza processos de concessão, negociação e adaptação necessários ao bem viver em Roraima.

Neste aspecto, o CTG Nova Querência foi e é agente e espaço de negociação no processo de inserção dos gaúchos à sociedade roraimense. A sua abertura e flexibilidade é vista como algo extremamente positivo e pertinente, e não como uma concessão, como se verifica nesta fala: "Graças a Deus, o CTG hoje na verdade é um termômetro, é um conciliador. [...] Hoje qualquer um que fala em CTG, não fala do CTG dos gaúchos, mas de uma associação voltada para a sociedade roraimense". Como um bom exemplo disso, a coluna social mais importante de Boa Vista noticiou, no dia 30-7-2005, o seguinte: "A banda Paçoquinha e outros grupos de forró convidados farão acontecer hoje à noite no CTG, o Forró do Mensalão". Por viver em Roraima e freqüentar o CTG, afianço não ser este um evento isolado. 
Da mesma forma, a manutenção de contatos individuais - no CTG ou não - também foi descrita como uma "necessidade" que deve ser permanentemente atendida. Um encontro, uma conversa com um outro gaúcho é um momento reparador, frente às carências geradas pelo processo de afastamento do lugar de origem, das referências sociais, culturais e familiares.

A vivência fora do "torrão", do "pago", expressões regionalistas por vezes pronunciadas com ênfase, propicia um novo olhar sobre muitas coisas, observando-se em algumas narrativas um tom crítico e/ou autocrítico. Alguns narradores ao serem instados a olhar o Rio Grande do Sul de fora, percebem o gaúcho muito fechado; que vive no Rio Grande do Sul em um mundinho muito pequeno, que refrata as coisas de fora, em prol da tradição e das próprias coisas de dentro do estado. A interação cultural proporcionada pela migração foi considerada, de maneira geral, como benéfica. Possibilita a revisão de noções e de padrões, como por exemplo, o histórico preconceito em relação aos nordestinos ou a hiper valorização das coisas sulinas.

A definição de uma identidade é aspecto funcional, pertinente e necessário quando se vive em outro lugar. Apareceu de maneira afirmativa em todas as narrativas, como nesta fala:

"Eu acho que é um privilégio, eu tive uma lição de vida aqui, adoro esta terra, cultuo a tradição, eu sou daqueles gaúchos que participam, sou da patronagem, mas eu nunca esqueço as minhas raízes; eu adoro esta terra e acho que só vou embora se me correrem".

Naturalizar as coisas é torná-las compreensíveis. Ao ressignificar e entrecruzar o lugar de origem e o de adoção, os narradores justificam a permanência e o enraizamento em Roraima, assim como a manutenção de sua identidade individual e filiação regional. Esta é uma situação previsível nos processos de inserção em um outro ambiente social. No entanto, no momento da narrativa torna-se um recurso fundamental, explicativo de comportamentos, de ações, de decisões, de negociações e de concessões, enfim, a tudo que, em última instância, dá sentido a vida no presente.

\section{Referências}

BOURDIEU, Pierre. O poder simbólico. 4. ed. Lisboa/Rio de Janeiro: Difel/Bertrand, 2001.

BRANDÃO, Carlos Rodrigues. O sentimento do mundo: memória, destino e cenários da vida entre errantes mineiros. In: As faces da memória. Campinas: 
CMU/Unicamp. (Coleção Seminários 2).

CONZEN, Kathleen Neils et al. The invention of ethnicity: una lettura americana. Altreitalie, Torino, Fondazione Giovanni Agnelli, anno 2, n. 3, apr. 1990, p. 4-36.

DE CERTEAU, Michel. A invenção do cotidiano 1: artes de fazer. Petrópolis: Vozes, 1994.

FELDMAN-BIANCO, Bela; HUSE, Donna. Entre a saudade da terra e a América: memória cultural, trajetórias de vida e (re)construções de identidade feminina na intersecção de culturas. In: As faces da memória. Campinas: CMU/Unicamp, p. 25-60. (Coleção Seminários 2)

FRASER, Ronald. Historia Oral, Historia Social. Historia Social, n. 17, outoño 1993 (Inst. Historia Social, UNED, Valencia), p. 131-139.

HALL, Stuart. Quem precisa da identidade? In: SILVA Tadeu (Org.). Identidade e diferença: as perspectivas dos estudos culturais. Petrópolis: Vozes, 2000.

JOBIM, José Luís. Formas da teoria: sentidos, conceitos, políticas e campos de força nos estudos literários. Rio de Janeiro: Caetés, 2003.

JODELET, Denise. La representacion social: fenomenos, concepto y teoria. In: MOSCOVICI, Serge. Psicologia social, II. Barcelona: Paidós, 1988.

POLLAK, Michael. Memória e Identidade Social. Rio de Janeiro, Estudos Históricos, v. 5, n. 10, 1992, p. 200-212.

SILVA, Tomaz Tadeu da. A produção social da identidade e da diferença. In: SILVA, T. T. (Org.). Identidade e diferença: a perspectivas dos estudos culturais. Petrópolis: Vozes, 2000.

SOUZA, Carla M. de. Do Chuí ao Oiapoque: migrações de de gaúchos para Roraima. Dissertação de Mestrado em História. PPGH/PUCRS. Porto Alegre: 1997.

— Gaúchos em Roraima. Porto Alegre: EDIPUCRS, 2001. (Coleção História, 42)

- História, História Oral e os historiadores. Histórica, Porto Alegre, n. 6, 2002.

História, memória e migração: processos de territorialização e estratégias de inserção entre migrantes gaúchos radicados em Roraima. Tese de Doutorado em História. PPGH/PUCRS. Porto Alegre: 2004.

THOMSON, Alistair. Histórias (co)movedoras: história oral e estudos de migração. Rev. Bras. Hist [online], 2002, v. 22, n. 44 [citado 17 nov. 2003], p. 341-364. Disponível em: <http://www.scielo.br/scielo>. ISSN 0102-0188.

TODOROV, Tzvetan. O homem desenraizado. Rio de Janeiro: Record, 1999.

WOODWARD, Kathryn. Identidade e diferença: uma introdução teórica e conceitual. In: SILVA, Tomaz Tadeu (Org.). Identidade e diferença: a perspectivas dos estudos culturais. Petrópolis: Vozes, 2000. 
